\title{
Article:
}

\section{Expert views on how language education may develop in the next 20 years and what CALL could contribute*}

\author{
Ton Koenraad \\ TELL Consult (The Netherlands)
}

ton.koenraad @ gmail.com

\begin{abstract}
The celebration of EUROCALL's twentieth anniversary provides a proper occasion to reflect on the future of language teaching and the role of CALL in these developments. In this paper we present the views of six authorities on language teaching and learning from different EU countries. All of them have a special interest in CALL and/or are CALL experts and well respected EUROCALL members, such as the late Graham Davies. We present a selection of their observations based on a summary of the Skype interviews in which they contributed to a symposium entitled 'And now for another century of modern language teaching...' organised by the Dutch national Association of Language Teachers on the occasion of its first centennial in 2011. To provide a more global (or at least European) perspective, the interviewees were asked to cover the same topics that were central to the live panel discussion delivered by six Dutch participants representing a variety of perspectives: secondary and university teachers, students, curriculum experts and teacher educators. By way of preparation, all involved had been given a number of challenging statements related to some aspects of the discussion theme: the characteristics of the future learning environment, teacher, learner, pedagogy and technology. In this audio-supported document we will focus on interesting points of view particularly related to pedagogy and technology expressed in the interviews. A video report summary of the live discussion (in Dutch) is available on the limited CD edition with recordings of the centennial festivities. For an impression of the panel discussion and other symposium activities see this video report on YouTube.
\end{abstract}

Keywords: CALL trends, future of MFL education, expert views, panel discussion, educational trends.

\section{Introduction}

The Dutch national Association of Language Teachers (Levende Talen [Living Languages]) celebrated its first centennial on May 27, 2011. Part of the festivities was a symposium with the title: '...and now for another century of modern language teaching'. The focus point of this symposium was a panel discussion. Six Dutch participants (teachers, pupils, curriculum experts and teacher educators) shared their views on the future of mainstream language learning/teaching. As food for thought they were given the following introduction and reflections to the theme. In a 100 years' time... will there still be some thirty students in three rows in a classroom with a language teacher working their way through text- and workbooks during two or three weekly, fifty-minute periods? Or will the concept of classroom and form disappear and will school be more like a social meeting place? After all, learning can take place anywhere: in social networks, virtual learning environments, with the help of intelligent agents or a private teacher at a distance. On the other hand, we should take into account that changes in 
education have proven to be slow and that all our 2011 prophecies may well stand little to no chance to come true in the traditional classroom.

1. The future learning environment. What changes can be predicted about the 'learning environment'? What implications are there for schools and school buildings?

2. The future teacher. Will subject teachers $(\mathrm{f} / \mathrm{m})$ and their task load of some 26 lessons per week disappear in the next one hundred years? And if so, who or what will replace them? Will they become merely coaches assisted by robots to transfer knowledge?

3. The future student. Pupils have changed in the course of time. Nowadays they are less willing to just consume educational content. They prefer to find information themselves but distinguish between personal and school-related learning. Educational organisations may well teach students less knowledge in the future and increasingly rely on their skills to acquire knowledge and develop competences independently.

4. Future methodologies. What are the current views on how languages are taught. Will didactics in mainstream language courses still be driven by textbooks produced by educational publishers? Will there be alternative approaches to develop language skills? Will web-based and interactive materials replace the traditional means? Will there still be a place for paper-based materials?

5. Future technology. Technological developments are bound to continue the next one hundred years. How will this affect language learning and teaching? Will we be able to learn how to speak a foreign language with the help of L2 signals from external sources or a chip embedded in our brains? What other, possibly more realistic, technical developments will support future teachers and students in the second language acquisition process?

To provide a more global (or at least European) perspective Hayo Reinders (also being a native speaker of Dutch) was invited to join the live panel discussion and five more international experts were requested to be Skype interviewed individually and discuss the same topics that were central to the live panel debate.

The following colleagues from a variety of EU countries were approached by the present writer and accepted the invitation: Jozef Colpaert (Belgium), Nicolas Guichon (France), Andreas Müller-Hartmann (Germany), Andreas Lund (Norway) and Graham Davies (UK), who regrettably died a year later.

Below we summarize the key points of their views and observations about the symposium topics. The present document has links to the original audio sequences for a number of statements. Although the standard language was English, Colpaert and Guichon have been invited to use their mother tongues so as to also add a multi-lingual dimension to this venture.

\section{The views of the international experts on the symposium topics}

\subsection{Learning in the future learning environment}

Andreas Müller-Hartmann does not expect the learning environment to change dramatically in the short term because, for societies, schools are the spaces where the training of the future potential workforce takes place. Because of this interest, states consequently want to have as much influence and control over these institutions as possible [Müller-Hartmann, 1] This -in his view- is also testified by the relatively limited impact the 'traditional' educational renewal movements, such as Freinet, appear to have (had) on mainstream education [Müller-Hartmann, 2]. Nicolas Guichon finds it difficult, possibly even dangerous, to make predictions, but observes that technologies develop faster than the changes that take place in schools [Guichon, 1]. From his research on the integration of ICT in language teaching it appears that teachers understand the importance of ICT but it still takes them too much time to learn to use applications. It would therefore be desirable if also policymakers recognized the importance of ICT 
training in the curriculum of initial teacher training [Guichon, 2]. Whether language education as we know it today, with students in a class year system led by a teacher working their way through a textbook will alter fundamentally in the future he finds difficult to answer because schools as institutions do not appear to change that quickly. He hopes, however, that a more informal organization will evolve which can accommodate a more flexible way of grouping students and support project-based activities where the teacher's role is more coaching in nature. And also that language education does not exclusively take place in designated classrooms and where technological facilitation, currently still seen as an add-on, forms a natural part of the learning environment. In this respect he can see great possibilities for the use of mobile phones [Guichon, 8]. Graham Davies observes that the technology-based learning environment in the United Kingdom (UK) is developing rapidly. In particular, the Web and the interactive whiteboard have made major contributions to the ways in which new technologies are used in teaching foreign languages. [Davies, 1]. In response to our observation that the use of the computer as a means for (oral) communication is becoming more important in language education Andreas Lund elaborates on telecollaboration [Lund, 1] and sketches the future development of this concept towards speech communities, in which the role of the teacher is increasingly of an organizing and coaching nature. He sees great opportunities for these types of networks because then the language itself is central and contacts with others and other communities can occur time and place independently. Regarding the implications for the curriculum he expects [Lund, 2] that learning objectives will guide planning and organizing the related online meetings. Jozef Colpaert starts off by saying that the order of the symposium propositions, with the learning environment as a starting point, is well chosen [Colpaert, 1]. It also matches well with his own views. Experience has shown that first the entire learning environment must be well designed before choices as to technological instrumentation can be made. Another aspect that he considers of great importance for the learning environment is the role of the teacher. Also to have a stimulating start of his presentations Colpaert often states that it takes a well-supported teacher to realize learner-centred education. After all, a learning environment that causes emotional and/or cognitive friction for teachers is counterproductive. Furthermore, he points out [Colpaert, 3] that the methodological approach itself is also part of the learning environment. And that consequently the local context should be analysed first before a particular method (e.g., cognitivistic) is chosen. For Colpaert a method consists of 3 parts: a teaching, a learning and an evaluation model, each defined in detail. For him the strength of a learning environment therefore is determined by the extent to which it is well matched to a specific local context [Colpaert, 4]

\subsection{The future teacher}

Davies expects that teachers will increasingly be developing their own materials thanks to the availability of software tools and the related competencies developed in teacher education [Davies, 15]. Furthermore he expects participation in Personal Learning Networks (PLN) as a form of continuing professional development to contribute to the development of skills needed to manage the "open classroom" [Davies, 16]. Although Lund expects the book as such will survive, he [Lund, 6] doubts - in contrast to MüllerHartmann- if coursebooks, also in their hybrid form with media and Internet content supported components, are here to stay. The web offers loads of materials. At the same time this very vast supply of information makes that teachers will not become redundant: youngsters can find lots of content but the teacher is still needed to support the process of meaning making. Related new teacher competences that he [Lund, 7] mentions include the ability to design learning environments, curriculum trajectories and communication activities based on an understanding of the effects of the choice of technologies to the learning and communication process. Colpaert considers it of great 
importance that teachers take pride in their work and are able to feel comfortable in their learning environment [Colpaert, 2]. He expresses the hope that future teachers whatever the specific attributes of their role - can work in an environment where they can be themselves, experience little friction and can be proud of their work (selfefficacy) [Colpaert, 5]. In that context, he argues for a greater role for teachers themselves to contribute to the quality improvement of the learning environment in which they operate, in a systematic way (educational engineering). He invites them to actively participate in improvement of the quality of the learning environment in which they operate [Colpaert, 5.1] Müller-Hartmann also attaches great value to the teacher's comfort zone [Müller-Hartmann, 12]. He therefore calls for more attention in initial training and more time in professional development programmes for familiarisation with, both personally and professionally, innovations such as more learner-and taskoriented approaches and technology-enhanced telecollaboration [Müller-Hartmann, 14].

\subsection{The future student}

Although Davies [7] agrees with the suggestion that extra demands are made on your motivation to learn foreign languages when English is your first language he regrets that students in the UK are no longer obliged to continue studying a foreign language beyond the age of 14, i.e. after their third year of secondary education. Attempts have been made by the Department for Education (DfE) to encourage students to continue with languages beyond the age of 14. An example is the online MYLO project, which was set up with the aid of substantial government funding. In his view it appears that MYLO is not having a major impact [Davies, 6]. Lund and Guichon see an increase in informal learning because students use social media and so called web 2.0 applications. Guichon's research shows that Facebook is popular among Lycée pupils and that its use also leads to (more) collaboration between students outside the school context (Guichon, 2012b). In his reaction to the suggestion that this type of informal learning could be integrated in formal, school-based learning, he points to the danger that "schoolification" of such Web 2.0 use could spoil its attractiveness for students [Guichon, 5]. Although also Müller-Hartmann observes that students nowadays make functional use of foreign languages (possibly English in particular) in technologically mediated contexts (SMS, blog, Facebook, gaming) it is his opinion that integration of such media in the school context only makes sense if the methodological approach is less forms and structure focused but that content and technological resources that appeal to students get a more central position [Müller-Hartmann, 13]. He also reports a growing interest in early language learning in Germany, in line with the developments globally in this respect and as also reflected by the number of registrations for the related educational master studies at the Faculty of Education at Heidelberg University of Applied Sciences [Müller-Hartmann, 5]. One of the implications is the need to improve the transition between primary and secondary education. To this end the EU project PriSECCO, coordinated by Heidelberg Faculty of Education, aiming for better conditions for the realization of a consistent learning trajectory between these sectors, developed materials (i.e. bridging tasks) to promote a better understanding of the dominant teaching approach in both sectors. In his view more specific attention for this topic is needed in initial and in-service teacher training programmes [Müller-Hartmann, 6]. And more in general Müller-Hartmann (for whom teacher training is a special interest) emphasizes that there should be a better integration of theory and practice and more emphasis on teaching skills in the teacher education curriculum, especially for first grade teachers [Müller-Hartmann, 7]. One of the essentially needed changes in language education, according to Colpaert, is more attention to the personal goals of the learners (the psychological shift). In his view there has been too much focus on standard curricular learning objectives in the past. Experiences in his projects show that the design of the learning environment must be aligned to the common features of the 
personal goals of a specific group of learners. Reinders shares the view that language education needs to become much more student-centred. Referring to higher education he finds that students - although they do not necessarily know how to study languages or do so autonomously - they know perfectly well that what they are being offered is not necessarily related to reality. Neither in terms of the teaching methods being applied and the way they are expected to learn, nor in terms of the actual knowledge and skills they are developing. To illustrate this point he mentions some features differentiating developing work-related written documents from producing an essay at university: time constraints, multiple-versions, not necessarily 'perfect', produced in collaboration and with a much more practice-oriented content and structure. With a view to the increasing availability of alternative options for developing language skills he expects students to become more critical about investing their time in programmes that do not appear to fit their needs.

\subsection{Future language learning pedagogy}

Regarding changes in the educational field Müller-Hartmann [8] observes that the communicative, task-oriented approach is gaining ground, at least at the level of the (international) research community. In his own practice he notes that the related principles and associated teaching methods appeal to and provide practical guidance for practitioners and student teachers. In his view the task-oriented approach offers more opportunities to address heterogeneity in classrooms and he is pleased to see a growing number of studies focused on the realities of the classroom in the field of language education studies. With respect to this approach he prefers the term task-supported to task-based language teaching. As most textbooks currently in use are not grounded on task-based related design principles, initial and in-service teacher training should be in alignment with the actual working conditions that teachers currently find themselves in [Müller-Hartmann, 9]. All the more since he expects that the commercially produced textbook will be in use for some time still [Müller-Hartmann, 10]. An important consideration here is that the use of alternative methods involving technology (however interesting for language education) results in working conditions that are not safe enough for the current generation of teachers [Müller-Hartmann, 11]. This is partly due to the fact that working with a more learner-and task-oriented approach is inherently less secure than delivering a more forms-oriented curriculum. But is also related to the limited content and experiences offered to this issue in initial training. He therefore advocates [Müller-Hartmann, 12] professional development formats that provide the time and support needed for a gradual development of the required competencies. Lund [8] too observes a growing influence of the task-oriented approach, also in classroom practice and on the materials recently produced by the publishers. He can see a future for a task-oriented approach, on condition that the tasks are designed so that they cannot be completed by simply copying and pasting (Lund, 2013). Future methodology development -in his view- will also need to be based on theoretical models such as Activity Theory, which includes the study of use of cultural instruments. Regarding language teaching in the UK Davies remarks that the restrictive and prescriptive National Curriculum, especially in England, offers teachers little room for choice of content and methodological experimentation. [Davies, 2]. Many teachers are not too happy with the content of the prescribed curriculum: it is too rigid and too focused on memorisation, with inadequate provision for developing understanding of grammar and syntax. [Davies, 3]. The current methodology can be characterised as topic-based rather than task-based [Davies, 4]. The provision of early language learning in primary schools from the age of 7 years is increasing, but the situation is confused and quality varies greatly from school to school, with the result that secondary school teachers do not know what to expect from incoming students. Regarding the possible impact of innovations in the methodological domain Guichon observes a growing interest in 
bilingual education or Content and Language Integrated Learning (CLIL) in a number of educational sectors and he expects the Common European Framework of Reference for Languages (CEFR) and the task-oriented approach will influence the approach of teachers and how publishers will design materials. [Guichon, 7]. Although Davies [13] would welcome this development he does not expect rapid growth of bilingual education in the UK. One reason for this, in his opinion, is the fact that language teaching is considered to be different from other school subjects. He compares it to learning to play a musical instrument as this also requires a lot of practice [Davies, 14]. Lund [9] characterizes bilingual education (CLIL) as an approach that will probably be important for future educational models where learning objectives are central and (foreign) language learning can be part of the means to realise them. Müller-Hartmann expects [3] that languages will continue to be taught as school subjects but that there will be changes in the range of languages that will be offered. On the other hand he reports that also in Germany there is a growing interest in CLIL [Müller-Hartmann, 4]. Recently, also in combination with subjects such as sports and music, because of the reduced cognitive load. And he considers the evidently motivating effect that a focus on content - one of the characteristic features of a CLIL approach has - also to be of great relevance for regular language teaching. According to Guichon language teachers should not attempt to integrate informal learning that could take place with the help of web 2.0 applications in education [Guichon, 6]. Lund, when asked about the significance of informal learning, recognises that the environment where knowledge is gained has indeed changed - school is just one part of that all- but he, too, thinks that education should not try to imitate those activities nor try to integrate the private world into school life. On the other hand, the professional community should study how images are used and what role language plays for communication in the applications that young people make use of such as games and 3D virtual worlds [Lund, 4]. Another implication, according to Lund, is that learning and communication strategies will need to have a much more central place in the curriculum because they are so important to the developing new genres where content is jointly created such as multilogues (as in dialogues but with multiple participants) and wikis (Lund, 2008) as here aspects such as turn taking are certainly as critical to the process as in face-to-face communication [Lund, 5]. In the same vein Reinders elaborates on the related concept of 'autonomous learning'. [...] 'A common misconception is that autonomous learning is restricted to learning. However recent research shows that it includes the relationships that an individual develops, the skill to learn with and from other others and the interactions that are involved'. And therefore autonomous learning, in his opinion, is about interdependence rather than just independence. And, like Lund, he advocates for more attention to the development of autonomy in the curriculum. Although currently not widely in use Guichon would like to see a (further) increase of the use of WEB 2.0 applications (Guichon, 2012a) and telecollaboration in schools, because this activity and related applications offer both interesting language practice opportunities and also a chance to address intercultural aspects [Guichon, 4]. Colpaert [7] does not expect that there will be significant changes in language teaching methodologies in the short term. The socio-constructivistic approach (e.g. in Belgium / Flanders) has not yet been fully implemented. Moreover, the choice for a specific methodology depends on contextual features and the characteristics of the target group. He illustrates this with a case from his own consultancy practice. Like Lund, Colpaert notes [8] that the insights from other scientific disciplines e.g. second language acquisition and psycholinguistics research although they could contribute significantly - are not yet sufficiently integrated in modern foreign languages (MFL) pedagogy. Also other research themes such as (cultural) identity psychology and the influence of mother tongue (education) could, in 
his opinion, [Colpaert, 9] contribute to our understanding of how contextual factors are related to the effectiveness of the learning environment.

\subsection{Technology of the future}

Lund thinks that communicative use of language will get a much more central place in the curriculum thanks to Web 2.0 applications. Lund who, like Mary Swain convinced of the importance of language production for language acquisition, expects that technological developments that can support social networks and facilitate collaborative dialogue will allow us to organise language education so that the actual use of language gets a much more prominent place [Lund, 3].

Both Guichon [9] and Davies expect that mobile technologies will provide convenience, flexibility and interesting applications to support Mobile Assisted Language Learning (MALL) once costs have been reduced [Davies, 12]

Müller-Hartmann shares the view that recent technological developments have greatly facilitated telecollaboration and with it increased the chances to open up the classroom to the outside world. But again, as these types of project activities are relatively 'unsafe' for teachers [Müller-Hartmann,14] -certainly compared to the regular course of business in the classroom- good teacher training including practical personal experiences in this domain are of great importance. If teacher education succeeds in providing student teachers with valuable telecollaborative experiences then the related 'emotional anchors' will increase the chance that they will use the technologies required for this purpose in their future professional practices.

Guichon observes that although the ease of ICT use increases so does the speed at which technology is changing. It is anticipated that the new generation now entering the teaching profession has the basic affinity with ICT required for coping with this in a flexible way [Guichon, 3].

Although the UK has quite a good reputation in the field of innovation [Davies, 8] - see for example the activities of CILT or the blogs of individual teachers like Joe Dale and José Picardo - the poor position of foreign languages in the school curriculum is clearly not a very stimulating factor.

Davies [9] follows numerous blogs set up and maintained by language teachers who describe their practice and their use of a variety of applications. The use of ICT in teaching foreign languages is required by the National Curriculum [Davies, 5], but in addition there is a very enthusiastic group of language teachers who make creative use of ICT, e.g. to support content presentation and language production. [Davies, 10]

Other technologies mentioned are touch-screens [Davies, 11] and translation tools. Guichon [10] expects - now that tools like Google Translate are getting better- that they will have an impact on language teaching particularly because these technologies can provide an important contribution to the (acceleration of) development of intercultural understanding. Invited to comment on the topic of technology Reinders states: [...] 'I often get asked what I think will be the next 'big thing' in language education. Of course I do not know but I do see that a number of developments are starting to come together that are opening up opportunities for ways of learning and teaching as well as monitoring and supporting them, that were previously difficult to achieve. Take, for example, developments in mobile learning. We have had portable phones for many years now. We have also had access to information through the internet. We now also have mechanisms to link those two with information about you as a user, your preferences and your location, and all this is starting to connect to your social identity too. This makes forms of individualised, situated and distributed learning possible, the potential of which we have only started to scratch the surface of. So in a sense I think 
the near future is more about the consolidation and integration of different technologies and a recognition of the ways in which they start to (in some ways quite naturally) appear in, or even create new learning ecologies. At the same time our understanding of these developments has grown to a point where different fields are starting to connect and form natural connections, such as those between social constructivist learning theories, second language acquisition and research into the ways which computer-mediated communication (and in particular more recently mobile learning) connect with these. So in a way I am hopeful that new developments continue to lead to new insights'. For more background information on his statement on technology, specifically on topics such as autonomy, MALL and informal learning Reinders refers to text sequences he published earlier: [...] Technology has the potential to not only provide access to resources for learning in a superficial sense, but also to offer increased affordances for autonomous learning.

Opportunities for interaction, situated learning, and support for learning outside formal contexts, have greatly improved because of technology. These affordances are not always capitalised on yet but offer the opportunity to support the learning process, in addition to simply providing the building blocks for it. At a superficial level, computers are good at monitoring students' engagement and progress, and programmes exist that use this information to guide learners and encourage them to make decisions about their own learning (Reinders, 2007). More recently, and perhaps more liberatingly, mobile technologies allow learners to have access to resources in out-of-school contexts (Kukulska-Hulme \& Traxler, 2005), potentially linking affordances in the environment with immediate support. As a result, there is now a much richer appreciation of the role of learning outside the classroom (Benson \& Reinders, 2011), not only in terms of the time learners spend learning, practising and of course using the language in non-formal learning environments, but also in the ways in which educators can prepare learners for, as well as guide them in such learning.

A reconceptualisation of language education as the provision of a collection of affordances that start from the learners as individuals, and include classrooms, materials, native speakers, teachers, assessment, other learners, the workplace, and so on, has been made more practically feasible, and methodologically easier to investigate, through the pervasive use of technology. We therefore gradually see a shift in our understanding of autonomy as a rather vague set of skills or attitudes, to more specific abilities to navigate different (learning) environments, with technology playing an important facilitative role. In addition, technology has revealed the extent and importance of the social networks learners engage in, and their effect on what and how people learn. This has helped researchers and practitioners to learn more about what it means to be an autonomous learner in practice. But technology also places constraints on the development of autonomy (Reinders \& Hubbard, 2012). As mentioned above, access to, for example, authentic materials or native speakers can be detrimental if learners are not prepared or supported for this. Reliance on technology can, for example, discourage learners from remembering new vocabulary when they have direct access to an online dictionary. Technology can also give students a false sense of development; online games, for example, have a great deal of potential for language practice (Gee, 2003), but can be limited in terms of genre and domains and may not push learners to engage in other types of communication that are also important, such as extensive reading, or writing a longer text. Colpaert [10], finally, sees a more limited impact of technological developments on language education as choices in this domain, also in the near future, represent "only" one aspect of the whole of the learning environment. In his work in the field of design and research of Computer Assisted Language Learning (CALL) he uses as a guiding principle: "No technology inherently possesses an effect on learning". He then explains why an ecological shift in CALL is 
needed: in the past, in evaluation research, the perspective was too limited, evaluating the effects of individual technologies on specific aspects such as attitude.

\section{Conclusion}

When we focus on the common aspects in the views of these six experts, a trend appears to emerge with a number of characteristics. Key elements of future modern language teaching and learning that are mentioned are the increased focus on interaction, the (oral) use of the target language for communication based on authentic contexts and content. The related school-based processes are teacher orchestrated and increasingly facilitated by information and communication technologies. The speed at which innovation will take place is expected to be largely dependent on the availability of teachers with the necessary competences and willingness to function in the related learning environment.

\section{Acknowledgements}

We would like to thank the interviewees for their time and contribution to both the Levende Talen 2011 Centennial and the EUROCALL 2013 conference.

\section{References}

Benson, P. \& Reinders, H. (2011). (Eds.), Beyond the Language Classroom. The Theory and Practice of Informal Language Learning and Teaching. Basingstoke: Palgrave Macmillan.

Council of Europe (2001) Common European Framework of Reference for Languages (CEFR) http://www.coe.int/t/dg4/linguistic/cadre1_en.asp

European Association for Computer-Assisted Language Learning (EUROCALL) http://www.eurocall-languages.org/wordpress

Gee, J. P. (2003). What Video Games Have to Teach Us about Learning and Literacy. New York: Palgrave Macmillan.

Guichon, N. (2012a). Vers l'intégration des TIC dans l'enseignement des langues. Paris: Didier.

Guichon, N. (2012b). Les usages des TIC par les lycéens - déconnexion entre usages personnels et usages scolaires. STICEF. Vol. 19.

Kukulska-Hulme, A., \& Traxler, J. (Eds.) 2005. Mobile Learning: A Handbook for Educators and Trainers. Routledge

Lund, A. (2008). Wikis: a collective approach to language production. ReCALL, 20(1), 35-54. Lund, A. (2013). Collaboration Unpacked: Tasks, Tools, and Activities. In C. Meskill (Ed.), Online Teaching and Learning: Language and Culture: Bloomsbury Academic.

MYLO project. MYLO is a free KS3 and KS4 language learning resource developed for the Department for Education and run by RM Education. http://www.hellomylo.com

Pri-Sec-Co (Primary and Secondary Continuity in Foreign Language Teaching), EU project, 2007-2009.

http://eacea.ec.europa.eu/Ilp/project_reports/documents/comenius/all/com_mp_13402 9_prisecco.pdf

Reinders, H. (2007). Big brother is helping you. Supporting self-access language learning with a student monitoring system. System 35,1: 93-111. Basingstoke: Palgrave Macmillan.

Reinders, H. \& Cho, M. (2011). Encouraging informal language learning with mobile technology: does it work? Journal of Second Language Teaching and Research, pp. 3-29 
Reinders, H. \& Hubbard, P. (2012). 'CALL and autonomy. Affordances and constraints'. In: Thomas, M., Reinders, H., \& Warschauer, M. (Eds.), Contemporary CALL. New York: Continuum.

Vereniging van Leraren Levende Talen (Dutch national Association of Language Teachers) http://www.levendetalen.nl

\section{Contributors}

Prof. Dr Jozef Colpaert teaches Instructional Design and Educational Technology at the University of Antwerp. He is director R\&D of LINGUAPOLIS, the Language Institute of the University of Antwerp and editor of Computer Assisted Language Learning. Homepage: http://www.jozefcolpaert.net

Prof. Graham Davies (1942 - 2012) was employed as a Lecturer in German at Ealing College (later integrated into Thames Valley University) from 1971 to 1990 , and then as Director of the Multimedia Language Centre from 1990 to 1993. He was involved in CALL as from 1976. He was conferred with the title of Professor of Computer Assisted Language Learning in 1989 and functioned as the founder president of EUROCALL from 1993 to 2000. Homepage: http://grahamdavies.wikispaces.com

Dr. Nicolas Guichon is professor at Lyon 2 University in Language education. He is a member of ICAR research team (CNRS) and was the director of the Masters programme language education and CALL until 2012. Homepage: http://nicolas.guichon.pagesperso-orange.fr

Dr. Andreas Lund is Associate Professor at the Department of Teacher Education and School Research and Vice Dean at the Faculty of Education, University of Oslo, Norway. Homepage: http://www.uv.uio.no/ils/english/people/aca/andlund/index.html

Prof. Dr Andreas Müller-Hartmann is head of the English Department of the University of Education (Pädagogischen Hochschule) Heidelberg. Homepage: http://www.phheidelberg.de/englisch/personen/lehrende/prof-dr-mueller-hartmann.html

Dr. Hayo Reinders is TESOL Professor and Director of the doctoral program at Anaheim University in the United States and Editor-in-Chief of Innovation in Language Learning and Teaching. His most recent books are on teacher autonomy, teaching methodologies, and second language acquisition and he edits a book series on 'New Language Learning and Teaching Environments' for Palgrave Macmillan. www.innovationinteaching.org

\section{Notes}

* This is an extended version of Koenraad, A. L. M. (2013). Expert Views on How Language Education May Develop in the Next 20 Years and What CALL Could Contribute. In L. Bradley \& S. Thouësny (Eds.), 20 Years of EUROCALL: Learning from the Past, Looking to the Future. Proceedings of the 2013 EUROCALL Conference, Évora, Portugal. Dublin/Voillans: Research Publishing, pp. 141-148. 


\section{Editorial Board:}

Dr. Christine Appel (Universitat Oberta de Catalunya, ES) | Dr. Paul Bangs (London City University, UK) | Dr. Françoise Blin (Dublin City University, IE) | Dr. Angela Chambers (University of Limerick, IE) | Dr. Thierry Chanier ( Université Clermont 2, FR ) | Dr. Jozef Colpaert (University of Antwerp, BE) | Dr. Robert Fischer (Texas State University, USA) | Mr. Anthony Fitzpatrick (Consultant, UK) | Dr. John Gillespie (University of Ulster at Coleraine, UK) | Dr. Trude Heift (Simon Fraser University, Canada) | Dr. Phil Hubbard (Stanford University, USA) | Dr. Kristi Jauregui (University of Utrecht, NL) | Dr. Mike Levy (University of Queensland, Australia) | Dr. Peter Liddell (University of Victoria, Canada) | Dr. Robert O'Dowd (Universidad de León, ES) | Dr. Pascual Pérez-Paredes (Universidad de Murcia, ES) | Dr. Joan Tomàs Pujolà (Universitat de Barcelona, ES) | Dr. German Ruiperez (Universidad Nacional de Educación a Distancia, ES) | Dr. Bernd Rüschoff (University of Duisburg-Essen, DE | Dr. Mathias Schulze (University of Waterloo, Canada) | Dr. Bryan Smith (Arizona State University, USA) | Dr. Peppi Taalas (University of Jyvaskylä, FI) | Mrs. June Thompson (University of Hull, UK) | Dr. Steven Thorne (Pennsylvania State University, USA) I Dr. George S. Ypsilandis (Aristotle University, GR) |

The EUROCALL Review is published online biannually by the European Association for Computer-Assisted Language Learning (EUROCALL) and is hosted online at http://www.eurocall-languages.org/review/index.html and at the Universitat Politècnica de València (Spain). Regular sections include:

- Reports on EUROCALL Special Interest Groups: up-to-date information on SIG activities.

- Projects: reports on on-going CALL or CALL-related R\&D projects in which EUROCALL members participate.

- Recommended websites: reports and reviews of examples of good practice in language learning website development.

- Articles: research, reflective-practice or research \& development articles relating to CALL and TELL.

- Publications by EUROCALL members: reviews of new books, CALL software, etc. published or edited by members.

The EUROCALL Review is indexed in ERIC (Education Resources Information Center - an internet-based digital library of education research and information sponsored by the Institute of Education Sciences of the U.S. Department of Education.)

Articles submitted to The EUROCALL Review are peer-reviewed by members of the Editorial Board.

If you can provide information on any topic of interest to the CALL community, please send this directly to Ana Gimeno, email agimeno@upvnet.upv.es

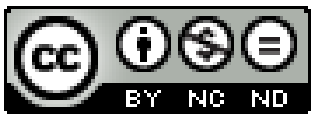

The EUROCALL Review, edited by Ana Gimeno, is licensed under a Creative Commons Attribution-NonCommercial-NoDerivs 3.0 Unported License. 